\title{
INCLUSÃO SOCIAL/ESCOLAR DE PESSOAS COM NECESSIDADES ESPECIAIS: MÚLTIPLAS PERSPECTIVAS E CONTROVERSAS PRÁTICAS DISCURSIVAS
}

\author{
Ticiana Melo de Sá Roriz, Katia de Souza Amorim e \\ Maria Clotilde Rossetti-Ferreira ${ }^{1}$ \\ Faculdade de Filosofia, Ciências e Letras de Ribeirão Preto - USP
}

A inclusão social aborda questões como respeito às diferenças e à participação igualitária dos cidadãos. No caso de crianças com necessidades especiais, a inclusão abarca sua participação na sociedade em geral e, particularmente, em instituições de educação regular (inclusão escolar). Dada a relevância, atualidade e controvérsias, fez-se um estudo empírico e, dentro deste, um levantamento bibliográfico, a ser aqui apresentado. Palavras-chave foram investigadas no MEDLINE, PsycInfo e LILACS, principalmente de 1996-2003. Selecionaram-se trabalhos em periódicos, que tratam da inclusão de pessoas com necessidades especiais e/ou da prática dos profissionais de saúde nessa área. Recuperaram-se 19 artigos, 11 empíricos, conduzidos a partir de diferentes métodos de registro e análise. O tema mostrou-se polêmico, alguns, inclusive, defendendo a segregação. Profissionais de saúde ocupam lugar destacado, mas alguns autores valorizam também atividades fora do setting terapêutico. O estabelecimento de diagnósticos é visto paradoxalmente: tratamento/rotulação. A cultura é apontada como tendo papel central. Ainda, pessoas com necessidades especiais praticamente não são ouvidas. O que se evidencia é que, por se tratar de um processo social complexo, este deve ser discutido e efetivado com a

1 Endereço para correspondência: Rua Martinico Prado, 677, apto. 81, CEP 14.050-050. Ribeirão Preto, SP. Fone: (16) 3931-3615. CINDEDI (Centro de Investigações sobre Desenvolvimento Humano e Educação Infantil), da Faculdade de Filosofia, Ciências e Letras de Ribeirão Preto, USP. Endereço eletrônico: ticianamelo@gmail.com, katiamorim@uol.com.br, mcrferre@ffclrp.usp.br 
participação de todos, para que pessoas com necessidades especiais, de fato, sejam capazes de participar e assumir nova posição social.

Descritores: Inclusão escolar. Necessidades educativas especiais. Profissionais da saúde.

\section{Introduzindo a questão}

discussão sobre inclusão social é de grande relevância em nossa soci-
Ledade, por estarmos vivendo em uma época em que o respeito à diversidade e a garantia ao direito à participação social de cada pessoa, a despeito de suas características (de gênero, étnicas, socioeconômicas, religiosas, físicas e psicológicas), têm emergido como uma questão ética, promovendo a reivindicação por uma sociedade mais justa e igualitária. Nesse sentido, a temática da inclusão social traz, como pressuposto, a idéia de uma sociedade que considera e acolhe a diversidade humana, nos diferentes tipos de atividades e nas diversas redes de relacionamentos, "estruturando-se para atender às necessidades de cada cidadão, das maiorias às minorias, dos privilegiados aos marginalizados” (Werneck, 1998, p. 108).

Essa questão tem sido colocada na ordem do dia em diferentes campos do saber e no espaço político-jurídico, nos últimos cinqüenta ou sessenta anos. Acreditamos que importante marco/motor, para mudança mais ampla, tenha se dado com o estabelecimento da concepção de "sociedade inclusiva”, firmada em 1990, pela Resolução 45/91, da Assembléia Geral da Organização das Nações Unidas (ONU, 1990).

Odom e Diamond (1998, p. 5) ressaltam, no entanto, que "não há uma definição comum sobre inclusão, havendo uma imensa diversidade de pessoas que a evocam como garantia de direitos”. Ela está nos jornais, outdoors, encontros científicos, nas conversas informais, na política. Fala-se em inclusão social, digital, cultural, econômica, escolar, desinstitucionalização, dentre outras.

Aqui, dentre os vários direcionamentos possíveis, deter-nos-emos naquele que foca pessoas com necessidades especiais, particularmente aquelas com algum 
tipo de deficiência física, mental e/ou sensorial. Dentro desse grupo de pessoas, que contempla também grande amplitude de questões e práticas, focalizaremos, especificamente, crianças com necessidades especiais.

Ao considerarmos a inclusão de crianças com necessidades especiais, porém, somos automaticamente remetidos ao campo da educação e às suas inúmeras práticas discursivas, as quais atualmente vêm sendo abordadas, dentre outras formas, através da inclusão escolar. Vale mencionar que essa separação entre inclusão social e escolar se trata de uma separação artificial, já que não há como cindir as duas, ambas fazendo parte de um mesmo processo social. A apresentação aqui separada é feita apenas de forma didática, em função de que cada uma delas tem sido estudada, preferencialmente, por campos de saber diversos, fazendo com que o enfoque e as questões abordadas possam de alguma maneira diferir.

Para situarmos historicamente as reformas na área da educação, no Brasil, apontamos que, primeiramente, surgiram as "escolas especiais" ou "centros de convivência”, destinados exclusivamente às "crianças especiais” (na década de 1950, foram criadas as primeiras APAEs) (Ferreira, 2004). Surge, em um segundo momento, apresentada na Lei 5692/71 (Brasil, 1971), a “integração escolar”. Instituíram-se então as "classes especiais”, sendo estas, salas de aula dentro de escolas regulares, destinadas às crianças com necessidades especiais. Finalmente, desde há alguns anos, há um novo movimento que busca a "inclusão escolar" e entende que crianças com e sem necessidades especiais deveriam ocupar uma mesma sala de aula. Marco/motor na constituição do discurso da "inclusão escolar" tem sido citado como ocorrido a partir da "Conferência Mundial de Necessidades Educacionais e Especiais: acesso e qualidade”, organizada pela ONU, em Salamanca (Espanha), em 1994. O princípio que guia a resultante Declaração é de que escolas regulares devem acomodar a todas as crianças, independente de suas condições físicas, intelectuais, sociais e emocionais (ONU, 1994). No Brasil, verifica-se que a "inclusão escolar" passa a aparecer em Leis, a partir de 1996 - como na Lei de Diretrizes e Bases da Educação Nacional (Brasil, 1996). 
Considerando-se a inclusão social ou, dentro desta, a inclusão escolar de crianças com necessidades especiais, entende-se que os profissionais de saúde representam mediadores importantes no processo de inclusão. Esses, de forma dominante, são destacados interlocutores junto às famílias, por elas procurados em função dos quadros, das limitações e/ou dificuldades da criança, o que os tem feito ocupar uma importante posição na abordagem e no encaminhamento dessas crianças.

Dada à atualidade e complexidade da questão, a qual se encontra imersa em contradições e conflitos, pela sua história, pelas múltiplas perspectivas, pelos diferentes interlocutores e instituições envolvidos, propusemosnos a investigar tais processos inclusivos de crianças com necessidades especiais, através do projeto de mestrado "A inclusão social e escolar de crianças com necessidades especiais, sob a óptica dos profissionais de saúde” (Roriz, 2002). Dentro dessa investigação, realizamos uma revisão bibliográfica sobre o assunto. É o resultado dessa revisão que aqui será apresentado.

\section{Revisão bibliográfica: uma busca pelos sentidos sobre inclusão na Literatura}

O objetivo da revisão foi fazer um levantamento, particularmente, a partir da produção de estudos empíricos, de modo a verificar como os temas da "inclusão social” e "inclusão escolar" são abordados na literatura. Ainda, em função do destacado lugar dos profissionais de saúde no processo de inclusão de pessoas com necessidades especiais, houve especial atenção à abordagem desse tema, a partir da perspectiva da saúde.

A revisão foi feita em três bases de dados: duas (MEDLINE e PsycINFO) procuraram verificar como o tema inclusão era abordado na literatura internacional; a terceira (LILACS) visou a analisar o impacto das publicações internacionais e o tipo de produção realizada no Brasil e em países latino-americanos.

As palavras-chave utilizadas foram "inclusion and preschool”, "inclusion and health", "inclusion and cerebral palsy", nas bases MEDLINE e 
PsycINFO; e, “inclusão e educação”, “inclusão e saúde”, “inclusão e Paralisia Cerebral”, no LILACS.

Os primeiros cruzamentos - ("inclusion and preschool" e "inclusão e educação”) se deram, na perspectiva da inclusão escolar; os seguintes (“inclusion and health" e "inclusão e saúde”), na busca de informações de como a saúde trata a questão, ou o que se diz sobre o lugar da saúde nessa temática; e, os últimos - (“inclusion and cerebral palsy” e "inclusão e Paralisia Cerebral”), em decorrência de uma priorização de crianças com Paralisia Cerebral como participantes da referida pesquisa de mestrado.

O levantamento compreendeu o período de 1996 a 2003, exceto a busca "inclusion and health" na base de dados PsycINFO, que foi realizada no período de 1978-2003. A extensão do período nessa revisão se justifica por se buscar acompanhar como tal temática vem sendo abordada através do tempo, considerando-se alguns marcos históricos, como a concepção de "sociedade inclusiva”, firmada pela Organização das Nações Unidas (ONU, 1990), e de “inclusão escolar”, da Declaração de Salamanca (ONU, 1994).

Adotamos como critérios de seleção: o veículo de publicação (periódicos indexados), os idiomas de publicação (inglês, espanhol, português), a modalidade de produção científica (trabalhos empíricos, teóricos e de revisão), as referências que versassem sobre inclusão de pessoas com necessidades especiais e as referências que fizessem reflexões acerca da prática dos profissionais de saúde na área.

Para viabilizar a busca, análise e discussão, foram utilizadas, também alguns critérios de exclusão. Foram, assim, eliminados os capítulos de livro, as teses e as dissertações; os trabalhos distantes do tema (como odontológicos, geriátricos, cirúrgicos). Também, os artigos que versassem sobre patologias específicas, como AIDS, câncer, esquizofrenia, Alzheimer; trabalhos que abordassem o tema da inclusão escolar de maneira essencialmente administrativa; ainda, trabalhos que tratassem da realização de atividades físicas por pessoas com necessidades especiais. Finalmente, foram excluídos os artigos que abordassem a Paralisia Cerebral num enfoque essencialmente médico. 
Os resumos que preencheram os critérios foram selecionados, tendo, porém, certa flexibilidade para incluir trabalhos que, embora não abordassem questões específicas das pessoas com necessidades especiais, pontuassem questões sobre o trabalho do profissional de saúde e da saúde em geral. Dessa forma, foram selecionados 37 artigos, sendo que, destes, 19 foram recuperados, sendo 11 empíricos.

Antes de discutir mais especificamente os artigos recuperados, apresentaremos um perfil do que foi encontrado sobre o tema, no conjunto do levantamento realizado.

\section{Panorama geral do levantamento a partir dos resumos}

Pela leitura dos resumos, pôde-se ter uma visão geral de quem tem investigado e de que tópicos relacionados ao tema "inclusão" têm sido contemplados. Em todos os anos analisados, os Estados Unidos foram o país com o maior número de publicações. A partir da década de 90 , porém, verifica-se que é cada vez mais freqüente a existência de publicações de outros países, dentre eles Canadá, Noruega, Inglaterra, Brasil, Austrália, Índia, Israel e Espanha (alguns com publicações únicas).

Os resumos que abordam algum aspecto da inclusão social surgem em 1984, com um pico nos anos 1999 e 2001. Inicialmente, o termo utilizado era “reintegração” à comunidade. O termo “inclusão” é usado pela primeira vez em 1989 e a expressão integração é usada pela última vez em 1992, quando é feito um paralelo entre os termos “inclusão" e "integração reversa” (Brasile, 1992).

A grande maioria dos resumos leva em consideração pessoas com algum distúrbio psiquiátrico. Apenas em 1992, surge um trabalho que aborda a inclusão de pessoas com cadeira de rodas no basquete (Brasile, 1992). A partir daí, surgem estudos que consideram a inclusão social de pessoas com síndrome de Down, mulheres deficientes, crianças cegas ou surdo-cegas etc.

A questão da inclusão escolar passa a estar em evidência a partir da década de 90. Nos anos de 1990 e 1991, foi identificado apenas um trabalho 
por ano, nessa temática, que se torna cada vez mais freqüente, de modo que, em 2001, já foram identificados seis resumos.

Antes de 1994, não há nenhum trabalho que utilize o termo "inclusão escolar”, sendo "integração” a denominação mais utilizada, ao se falar de reforma da educação. Atualmente, o termo inclusão é bastante difundido e continua sendo muito utilizado, seja como modelo de educação ideal ou no intuito de apontar falhas no processo.

Em todas as bases de dados, com as palavras-chave "inclusion and cerebral palsy”, a maioria dos trabalhos discute questões diagnósticas ou terapêuticas, como a aplicação de Botox, técnicas de fisioterapia, dentre outros. Dois estudos apresentam reflexões sobre a prática da inclusão dessas pessoas e serão discutidos mais detalhadamente adiante (Heller, Factor, \& Hahn, 1999; Lebeer \& Rijke, 2003).

Apesar de se verificar que, desde 1984, existem trabalhos que colocam as pessoas com necessidades especiais em foco, na maioria absoluta dos estudos, é mais evidenciada a opinião de outras pessoas, como educadores, diretores, colegas de sala e membros da família (tanto pais como irmãos). Somente a partir de 2000, três pesquisas trazem a opinião das próprias pessoas com necessidades especiais (Arbeiter \& Hartley, 2002; Cook, Swain, \& French, 2001; Repper, 2000), revelando como é recente o processo de buscar ouvir diretamente a opinião dessas pessoas.

A preocupação sobre o trabalho do profissional de saúde em equipe teve início apenas em 1992. Entretanto, é só a partir de 1997 que se começa a abordar a ligação desses profissionais com a prática da inclusão. A investigação da participação desses profissionais na inclusão escolar aparece apenas em um resumo de relato de experiência (Chapman \& Ware, 1999).

O que foi relevante, ao término dessa análise preliminar, foi a constatação dos diversos significados circulantes sobre inclusão, os quais marcam a prática do processo de inclusão social e escolar. Esses significados mostram-se claramente em construção e, simultaneamente, contribuindo para constituir todo um novo olhar aos processos de inclusão, marcados mesmo pela Resolução da ONU (1990) e pela Declaração de Salamanca (ONU, 
Ticiana Melo de Sá Roriz, Katia de S. Amorim e Maria Clotilde Rossetti-Ferreira

1994). Por outro lado, foi evidente a escassez de artigos que abordem a perspectiva da equipe de saúde com relação ao tema inclusão social e escolar.

A seguir, apresentaremos uma análise mais acurada, baseada nos artigos empíricos selecionados.

Aprofundando a análise por meio dos 11 artigos empíricos - algumas questões metodológicas

Dos 11 artigos empíricos recuperados, a fonte de publicação que apresentou o maior número de artigos que versassem sobre o foco do trabalho foi a revista Disability \& Society $(\mathrm{n}=3)$. Já quanto às instituições de pesqui$s a$, não havia mais de um trabalho realizado pelo mesmo centro. Tomandose como referência os critérios de inclusão e exclusão adotados, a produção brasileira parece escassa, já que não havia nenhuma publicação de modalidade empírica. O que encontramos foram dois artigos teóricos (Ghirardi, 2000; Oliver \& Nicácio, 1999), além de relatos de experiência.

Quanto aos procedimentos utilizados, a coleta por entrevista foi a mais freqüente, tendo sido realizada em oito dos trabalhos. Quatro destes associaram à entrevista, o procedimento de observação participante (Baker \& Donelly, 2001; Hanson et al., 1998; Lebeer \& Rijke, 2003; Rao, 2001) e um associou a gravação em vídeo aos dois outros procedimentos (Lebeer \& Rijke, 2003).

Análise documental foi realizada em três trabalhos, associada a outros procedimentos (Abrantes-Pego, 1999; Baker \& Donelly, 2001; Hanson et al., 1998). Três artigos trabalharam com questionários enviados pelo correio (Jones, Hampshire, Tweddle, Moult \& Hill, 2001; Kasari, Freeman, Bauminger, \& Alkin, 1999; Palmer, Borthwick-Duffy, Widaman, \& Best, 1998) e um trabalhou com falas que surgiram durante a confecção de um álbum pelos participantes da pesquisa (Cook et al., 2001).

Duas pesquisas utilizaram instrumentos de avaliação para averiguar variáveis. Especificamente, "Inventory for Client and Agency Planning (ICAP)”, “Depression Scale of the Psychopathology Instrument for Mentally Retarded Adults (PIMRA)”, “Cognitive Domain of the Client Development 
Evaluation Report” e "Maladaptative Behavior Section of the Behavior Development Survey” (Heller et al., 1999; Palmer et al., 1998).

Três trabalhos usaram estratégias quantitativas na análise de dados e oito usaram estratégias qualitativas. Os primeiros utilizaram diferentes análises estatísticas: um utilizou duas formas de análise - a análise de variância ANOVA e o teste de quiquadrado, sendo esse último também utilizado em outro trabalho. O terceiro artigo utilizou-se da análise MANCOVA. Dentre os de estratégia qualitativa, alguns utilizaram a análise do discurso ou conteúdo. Outros utilizaram a perspectiva ecológico-sistêmica, a abordagem etnográfica, dentre outros.

Com relação ao tipo de delineamento da pesquisa, nove artigos foram transversais. Apenas dois trabalhos acompanharam longitudinalmente os sujeitos-participantes. Destes, um fez o acompanhamento por três anos (Heller et al., 1999). O outro não especificou o período, mas fez entrevistas anuais com a família, além de gravações com crianças (Lebeer \& Rijke, 2003).

No que concerne aos sujeitos-participantes dos estudos, verificamos foco nas famílias de pessoas com necessidades especiais (6 artigos, a maioria com foco nos pais), nas próprias crianças com necessidades especiais (4 artigos), nos profissionais de saúde relacionados à inclusão (3 artigos), nos profissionais de saúde em sua prática clínica (2 artigos), em adultos com necessidades especiais (2 artigos) e em professores e/ou coordenadores da escola (2 artigos).

Com relação à forma de abordar a temática, os principais aspectos discutidos nos trabalhos analisados são apresentados a seguir.

Aspectos institucionais e humanos referentes à saúde

Os artigos que são primeiramente apresentados trazem reflexões acerca da prática dos profissionais de saúde, tanto na relação do clínico com o/a paciente como relacionados à qualidade do atendimento em serviços públicos de saúde. Apesar de não estarem voltados diretamente às pessoas com 
necessidades especiais, tratam de questões em que estas estão também implicadas, como potenciais pacientes desses profissionais/serviços.

Um dos artigos (Jones et al., 2001) trata mais diretamente dos profissionais de saúde. Os autores partem da premissa de que, atualmente, os pacientes são mais informados, pela facilidade de acesso à Internet, revistas, dentre outros, e que os clínicos não sabem lidar com esse novo padrão de paciente. Assim, realizaram um estudo clínico multicêntrico a fim de identificar as necessidades de aprendizagem de clínicos e os desafios organizacionais para satisfazer a necessidade de informação de pacientes, assim como, as oportunidades para clínicos aprenderem com os pacientes. Alguns achados do estudo trazem a importância de, por exemplo, priorizar a educação do paciente, entender os aspectos emocionais da aprendizagem, ajudar pacientes a entender sobre cuidado de saúde, trabalhar com questões da equipe multidisciplinar, dentre outros.

Os autores perceberam que, apesar de muitos clínicos ressaltarem a importância de habilidades de boa comunicação para a educação do paciente, essas representam apenas parte do processo de entendimento. Constataram que outras fontes são utilizadas, fugindo do controle do clínico, enfatizando a necessidade de se repensar maneiras de trabalhar, colocando o paciente no centro. Para tanto, mudanças organizacionais de novos sistemas são entendidas por eles como necessárias para dar suporte às mudanças na prática clínica.

Em outro trabalho, Abrantes-Pego (1999) estudou a complexidade da articulação entre poder e população usuária dos serviços de saúde, no Brasil, a partir de instâncias locais de participação social, impulsionadas pela descentralização de tais serviços. Foram realizadas entrevistas abertas com líderes da comunidade, com alguns dos diretores dos serviços de saúde e com os profissionais das instituições universitárias que trabalhavam na comunidade. Além disso, foram feitas análises de documentos oficiais e atas de reuniões dos líderes comunitários.

Foi verificado pela autora que, no contexto da transição, a saúde, entendida como um problema social urgente, possibilitou a mobilização de 
diferentes grupos sociais. Ela constatou que a exclusão dos usuários propiciou práticas clientelistas e manipuladoras nos serviços de saúde, que conduziram a uma situação de desconfiança por parte da população em relação aos políticos e a tudo o que vinha do Estado. A investigação possibilitou evidenciar o encontro conflituoso entre duas lógicas: a dos formuladores de políticas públicas e a da população. Concluiu-se que esse desencontro existe, dentre outros motivos, porque se implementam estratégias de participação que não levam em consideração as formas como os grupos sociais se organizam.

Referindo-se, porém, mais diretamente às pessoas com necessidades especiais, verificamos que diferentes autores pontuam aspectos diversos, os quais contribuem para circunscrever o desenvolvimento daquelas pessoas.

Circunscritores dos limites e possibilidades no desenvolvimento de pessoas com necessidades especiais

Um dos trabalhos recuperados (Lebeer \& Rijke, 2003) investigou especificamente os processos desenvolvimentais de 20 pessoas com lesões cerebrais, cujo critério de seleção era de que tais pessoas tivessem tido um "desenvolvimento funcional positivo, algumas vezes, completo ou, algumas vezes, em uma ou duas áreas, apesar da lesão cerebral severa” (p. 132).

Os autores exploraram a conexão entre o desenvolvimento cognitivomotor-social em crianças com lesões cerebrais e as interações e experiências no ambiente psicossocial. Eles verificaram que, para que as crianças adquirissem habilidades funcionais, elas precisavam de estimulação intensiva. Destacam, porém, que as atividades fora dos settings terapêuticos se mostraram também muito significativas. Ainda, os autores identificaram que as experiências das crianças, dos pais e dos cuidadores demonstraram processos altamente individuais, apesar de características comuns terem sido observadas: muitas crianças tinham períodos de passividade por tempo indeterminado, até que alguém as "acordava”, desafiando-as. Quanto aos familiares, verificaram que era dinâmica a maneira dos pais vivenciarem períodos importantes, eles próprios falando em períodos cíclicos: depressão, 
desespero total, conflitos com profissionais ou com a criança, falta de aceitação da condição, medo, raiva, seguidos por períodos de energia renovada por novas metas. Para os autores, passo importante parece ser que os pais se tornem mais atentos aos potenciais latentes e sinais de aquisição da criança, mais do que enfoquem na deficiência de seus filhos.

Os autores concluem chamando a atenção para dois aspectos. O primeiro, é que o desenvolvimento não parece acontecer espontaneamente, mas como resultado de interações complexas entre a criança e pessoas de seu convívio, em um ambiente estimulador. Assim, os autores entendem que o que familiares e cuidadores acreditam que a criança é capaz de fazer, acaba por ter forte influência nas suas ações e na conseqüente promoção do desenvolvimento. Um segundo aspecto é que o desenvolvimento não é considerado como linear, mas como tendo seu limite a priori desconhecido e seu resultado imprevisível. Nesse sentido, evidenciaram que testes realizados têm o risco de se tornarem uma "profecia”, e rótulos podem influenciar nos desempenhos escolares. Os autores concluem que avanços desenvolvimentais podem ser explicados pela plasticidade neuronal e pelo ambiente, incluindo familiares e amigos. Aliás, para eles, é desse complexo ambiente, no qual a criança está imersa, composto por familiares, amigos e profissionais comprometidos com a estimulação e mediação, que se pode constituir os limites e as possibilidades relacionados ao processo desenvolvimental.

O estudo etnográfico de Baker e Donelly (2001), por outro lado, teve como objetivo explorar a influência do ambiente na qualidade de experiências sociais de quatro crianças com síndrome do X frágil, morando em Sydney, Austrália. Os dados foram coletados em ambiente escolar.

Os autores evidenciaram três elementos que afetaram significativamente as experiências sociais das crianças. O primeiro foram as percepções de deficiência, sendo que as percepções negativas da comunidade tiveram efeitos nas experiências sociais dessas crianças. O segundo refere-se à família, considerada como influência poderosa nas experiências sociais de cada criança. A superproteção dos pais, que é sempre citada como obstáculo para as experiências sociais, neste estudo foi vista como se iniciando, exatamente, 
pela falta de suporte de médicos, terapeutas, amigos e familiares. O terceiro elemento de impacto identificado foi a escola. Esta foi confirmada como uma instituição social que tem uma influência significativa na qualidade das experiências sociais dessas crianças. Aspectos analisados com relação à escola mostraram que a maneira como a escola é organizada, além da conduta dos seus profissionais, pode levar à promoção ou não de oportunidades para interação entre crianças. Para os autores, as habilidades sociais talvez sejam pouco úteis, se o ponto de vista da comunidade é negativo, se a família não possui suporte para prover oportunidades sociais e se a escola não promove um ambiente adequado para se aprender novas habilidades sociais. Para eles, em cada tipo de escola (especial ou inclusiva) existe um ambiente único que influencia significativamente a qualidade das amizades e das interações.

Heller et al. (1999), finalmente, examinaram o ajustamento de 129 adultos (30 anos ou mais) com Paralisia Cerebral, transferidos de casas de repouso ("nursing homes”), para casas comunitárias (“community-based settings"), nos EUA, comparando os adultos transferidos com aqueles que permaneceram residindo em casas de repouso. As transferências efetivaramse em decorrência da Lei OBRA 87.

O que os autores verificaram é que, apesar da lei, a transferência de pessoas com Paralisia Cerebral tem sido lenta. Ainda, que a modificação nos padrões de inclusão na comunidade daqueles que se mudaram para as casas comunitárias foi muito pequena, com pouca participação na vida comunitária fora das casas. Alguns achados desse trabalho mostram-se interessantes, como o fato de que os adultos transferidos tiveram benefícios nas áreas de saúde e comportamento social, a despeito de ter ocorrido uma diminuição de cuidados médicos nas casas comunitárias. A mobilidade (andando/cadeiras de rodas) dos transferidos aumentou bastante quando comparada aos nãotransferidos.

Focalizando, porém, mais especificamente em crianças com necessidades especiais, verificamos que alguns artigos fazem reflexões de como tem ocorrido, ou não, sua inclusão escolar. 
Ticiana Melo de Sá Roriz, Katia de S. Amorim e Maria Clotilde Rossetti-Ferreira

\section{Inclusão Escolar - Múltiplas perspectivas e controvérsias}

Quatro estudos empíricos focalizaram, prioritariamente, aspectos educacionais relativos à inclusão das crianças. Em seu trabalho, Cook et al. (2001) investigaram os pontos de vista e as experiências de sete crianças de uma escola especial para deficientes físicos, na Inglaterra, a qual iria ser fechada devido à política de inclusão. Nesse trabalho, alguns aspectos foram reconhecidos, pelos próprios autores, como limitações do estudo. Uma das limitações foi o fato de que as crianças foram selecionadas pelos professores, por meio de critérios em parte desconhecidos pelos pesquisadores. Outra limitação é de que as crianças tinham que ser capazes de se comunicar verbalmente, devido ao curto período para realização da pesquisa (por causa do fechamento da escola).

Os resultados foram divididos em três tópicos. O primeiro é o que aborda a educação como uma experiência: as experiências das crianças na escola especial foram consideradas como positivas, estando mais relacionadas à qualidade da experiência do que às questões educacionais. Como exemplo, para os alunos, importava mais se o professor era "legal” ou alegre. O segundo tópico de reflexão dos autores foi considerar a inclusão como pertencimento, já que as crianças foram resistentes a falar da saída da escola e, quando o faziam, demonstravam raiva e tristeza. O terceiro foram os sentimentos de exclusão, pois alguns não acharam justo o fechamento da escola, nem para eles, nem para seus amigos.

Os autores concluem que, apesar da positiva meta de inclusão, a escola especial de origem representava, para as crianças, uma comunidade que oferecia segurança social, emocional e psicológica. A reorganização, em prol das próprias crianças, foi feita sem antes consultá-las, revelando um processo de inclusão que não leva em consideração o ponto de vista do deficiente.

Em outro trabalho, que investiga o contexto da inclusão escolar, Hanson et al. (1998), partindo de um referencial ecológico-sistêmico, examinaram como os programas pré-escolares e os locais da comunidade validam, adaptam e mesclam as preferências e/ou expectativas de 112 famílias e crianças, participantes da inclusão. Para tanto, foram entrevistados familia- 
res/cuidadores, professores/assistentes, diretores/coordenadores, sendo feitas ainda observação participante e análise documental. Os autores concluem que, para o sucesso de programas inclusivos, é necessária a manutenção de uma filosofia de aceitação da diversidade humana e a ênfase em valores de pertencimento e participação na comunidade. Nessa discussão, o papel da cultura surge como central, com reflexões sobre a interação, a cultura da sala de aula, as perspectivas da família e a cultura da comunidade.

Na análise sobre interação, Hanson et al. (1998) pontuam que a necessidade de ser aceito é comum e que as crianças buscam entender a cultura de seus pares. Além disso, quando as crianças são percebidas como diferentes, torna-se mais difícil para estabelecerem interações. Quanto à cultura da sala de aula, esses autores afirmam que os indivíduos que interagem nesse ambiente produzem e são guiados por uma rede de valores, crenças e práticas. Ressaltam o aspecto dinâmico dessa cultura da sala de aula, tendo em vista que os valores e práticas dos seus participantes, muitas vezes, podem ser diferentes e até mesmo conflitantes, fazendo com que haja tensões nesse espaço.

Quanto aos valores e crenças da família, estes são fundamentais para definir o entendimento sobre deficiência, as expectativas e as escolhas para a criança. Para os autores, mais do que a deficiência em si, a condição socioeconômica e cultural da família, junto com a etnia e o diagnóstico da criança, influenciam suas expectativas.

Observaram, ainda, que a maioria das famílias de crianças com e sem deficiência era receptiva aos programas inclusivos. Especificamente, as primeiras viam a inclusão como uma oportunidade de seus filhos aprenderem a viver no "mundo real”. A maneira como essas famílias participam de cada serviço, segundo os autores, está associada ao acesso à informação crítica e a serviços de suporte, os quais são influenciados pela linguagem, cultura, educação e diferenças econômicas. Dessa forma, famílias com limitado acesso à informação e a recursos teriam um papel mais passivo na educação de seus filhos, apresentando-se como mais confusas nas situações.

Os outros dois trabalhos empíricos, relativos à inclusão escolar, abordaram as percepções dos familiares quanto ao ambiente educacional inclusi- 
vo. Kasari et al. (1999), por um lado, investigaram se o diagnóstico e a idade da criança afetam a maneira como os familiares percebem o ambiente educacional para suas crianças, se eles percebem vantagens no modelo de educação atual do qual seus filhos participam e qual seria, para eles, o modelo considerado ideal. Questionários foram enviados anonimamente para membros de associações de pais. Participaram da pesquisa 113 pais de crianças com autismo e 149 pais de crianças com Síndrome de Down.

Os autores dividiram os resultados em vários itens. Um primeiro tratava das diferenças de grupos, não se identificando diferenças do nível de satisfação entre pais de crianças com síndrome de Down e pais de crianças com autismo. Um segundo referia-se às diferenças de idade das crianças. Nesse sentido, pais de crianças mais velhas (maiores de 5 anos) eram menos favoráveis à inclusão do que pais de crianças mais novas. Os autores atribuem isso a aspectos como a maior facilidade de acesso a esse tipo de programa por crianças menores e a possibilidade de estarmos vivenciando uma mudança de perspectiva nas percepções dos pais quanto à inclusão de seus filhos. Um terceiro aspecto trata das diferenças no modelo atual de educação, discutindo que pais de crianças que freqüentavam a educação regular mostravam-se mais satisfeitos que os pais de crianças que freqüentavam programas de educação especial. Os últimos mostravam-se ambivalentes em mudar de programa, por achar que seus filhos não terão, em uma escola regular, professores especializados e um curriculum apropriado. Finalmente, abordaram a questão do modelo de educação considerado ideal. Nesse sentido, os familiares que valorizam a interação com pares priorizam que as crianças sejam seguidas no ensino regular; todavia, os familiares que vêem os professores como vantagem dos programas educacionais preferem que suas crianças sejam seguidas na escola especial.

Os autores acreditam que, dentre as razões para as diferenças de opiniões de pais, esteja a preocupação com relação à proporção professoraluno, à qualidade do programa, à capacitação dos professores e à rejeição de seus filhos, sendo essa última mais freqüente em pais de crianças com autismo. Para os autores, as diversidades individuais das crianças justificariam essas diferenças de opinião. 
Palmer et al. (1998), também investigando o que influencia as percepções dos familiares com relação à prática inclusiva, estudaram 460 crianças com deficiência mental de moderada a severa, freqüentando salas especiais, em escolas públicas regulares. Apesar de as crianças estarem vivenciando o modelo de "integração", os autores queriam saber o que os pais pensavam sobre a "inclusão".

Na investigação, os autores constataram que as percepções eram influenciadas fundamentalmente por três aspectos. O primeiro se refere às características dos pais: do mesmo modo que Kasari et al (1999), os autores apontam que aqueles familiares que valorizam mais a socialização de seus filhos têm percepções mais positivas sobre a inclusão, enquanto que aqueles que dão um valor maior ao curriculum especializado, ficam mais apreensivos quanto à eficácia das práticas inclusivas. O segundo aspecto tem a ver com as características da criança: percepções positivas do impacto de práticas inclusivas são encontradas, quando atribuído à criança um funcionamento cognitivo mais alto, além de menores problemas de comportamento e de locomoção. Finalmente, destacam a história da inserção da criança no modelo de educação atual: o familiar de uma criança que passou a maior parte do tempo em escola especial associa mais percepções negativas à inclusão.

Finalmente, dois artigos, apresentados a seguir, detiveram-se na investigação das práticas e discursos que atravessam os processos de inclusão de pessoas com necessidades especiais.

\section{Práticas discursivas e os processos de Inclusão}

A partir de uma perspectiva das práticas discursivas, Goodman (2001) investigou 47 adultos, a maioria na faixa de 30 anos, sofrendo de doenças mentais e sendo tratados em clínicas de saúde mental, na comunidade Haredi (Israel, grupo ultra-ortodoxo). A meta era verificar como os investigados narram sobre a sua doença e como seus rabinos contam a história da "mesma" doença. Foram entrevistadas, também, 51 pessoas da sua rede social (esposas, mães etc.). 
A autora verificou que, numa mesma cultura, há um repertório de versões possíveis da doença mental. As narrativas escutadas pela pesquisadora refletem um padrão paradoxal: para os adultos com doença mental é melhor acreditar em algo sobrenatural. Dessa forma, eles lutam contra o medo da exclusão da sociedade "normal”. Os rabinos, por outro lado, não acreditam nisso, sobretudo pelo papel que exercem na comunidade. Assim, moldam suas versões e colocam os adultos com doença mental como desviantes, excluindo-os. Concluiu que, apesar dos indivíduos "escolherem e recriarem narrativas-chave em sua cultura, a escolha do que é dito é feita de acordo com a posição social” (Goodman, 2001, p. 188).

Nessa mesma linha, Rao (2001), refletindo sobre a inclusão de crianças, procurou entender como oito famílias bengali realizavam a inclusão de crianças com deficiência mental de moderada a severa, nas suas famílias e na comunidade. $\mathrm{O}$ foco da investigação dirigiu-se às mães. Durante a pesquisa, a autora percebeu a atribuição à criança, pelas mães, da palavra "inconveniência”, palavra essa que seria usada de maneira coloquial em situações diversas. Ela traria um sentido de dificuldades específicas de seus filhos, dificuldades essas compreendidas enquanto desafios não sem solução e sendo, inclusive, mutáveis com o tempo. A palavra seria usada também para que outras pessoas entendessem melhor os comportamentos de seus filhos. E, dado o caráter indefinido e não pejorativo do termo, dificultaria que as pessoas rotulassem a criança. As famílias buscariam enfatizar assim que a criança tem uma inconveniência e não que ela seja uma inconveniência.

Para a autora, a busca por palavras alternativas, feita pelas mães, caminha no sentido contrário ao do modelo médico, que, freqüentemente, se fundamenta em rótulos (diagnósticos), os quais contribuem para o processo de exclusão social. A autora acredita que o foco dos serviços, tanto médicos como educacionais, está na “deficiência” e que as famílias sabem melhor como lidar com isso e incluir seus filhos, porque sabem o que seus filhos fazem e são, além de serem “deficientes”. Daí, a autora apontar para a importância de que os programas de reabilitação aproveitem a riqueza dos recursos familiares, contrapondo-se à usual subestimação dos mesmos. Os 
pais têm a ensinar aos profissionais, por estarem em contato direto com a criança, com a comunidade local e sua cultura.

\section{3- Considerações sobre como o tema tem sido abordado}

Nos artigos selecionados, o tema inclusão foi percebido como presente ora de maneira mais enfática, ora menos aparente ou mesmo implícita, nitidamente, porém, representando uma questão polêmica, com profundas divergências de opiniões entre autores e, mesmo, entre os diversos sujeitos-participantes investigados.

No que tange às questões educacionais, identificam-se, com clareza, duas vertentes sobre as práticas inclusivas. Em uma delas, a valorização de certos aspectos - como presença de professores especializados, proporção professor-aluno e curriculum - é marcante para a não-aceitação de programas inclusivos. Em outra, a valorização da socialização e interação com pares leva à escolha pela participação em programas de inclusão. Acreditamos que essas divergências têm, como suporte principal, certas concepções sobre desenvolvimento humano. Dessa forma, aqueles que optam por escolas especiais parecem acreditar que a interlocução da criança com o adulto é que dará alicerce para o processo desenvolvimental; para aqueles que priorizam a inclusão, a interação entre pares parece ter maior relevância nesse processo.

Aliado a isso, as características da criança são entendidas como influenciando significativamente a percepção de seus pais, sendo que crianças que possuem maior facilidade na relação entre pares têm pais mais adeptos à inclusão. Ainda, a presença de deficiências associadas limita a perspectiva da inclusão escolar. Isso parece justificado pelas expectativas traçadas com relação a cada criança, expectativas essas baseadas não só nas características pessoais, mas também nos valores e crenças de cada família e na cultura da escola (Hanson et al., 1998; Palmer et al., 1998).

Nesse sentido, o próprio programa em que a criança já se encontra inserida é entendido como relevante, pois já pode ser correlacionado à percep- 
ção e às concepções dos familiares. No entanto, alguns autores são enfáticos no sentido de ponderar essa afirmativa, já que, para eles, há casos em que as opções são escassas, fazendo com que os pais não tenham escolha ou alternativa. Ou mesmo, que esses familiares não tenham acesso a informações relativas às diversas possibilidades existentes (Hanson et al., 1998).

Em nossa revisão, verificamos que as contradições extrapolam os limites da escola e atingem outros campos da vida social. Dentro de cada um deles, os trabalhos revelam que a cultura emerge como tendo um papel central, cultura essa entendida como práticas discursivas da comunidade onde crianças e famílias estão inseridas. Essas práticas se apresentam através da linguagem coloquial e profissional usada, dos lugares concedidos no seio da família e no conjunto social; pela rede de valores, crenças e práticas pelos quais esses indivíduos são guiados e que, simultânea e dialeticamente os produzem. Esses discursos e práticas têm concretude na maneira como se organiza a situação das e os papéis atribuídos às pessoas com necessidades especiais. Como indicam Goodman (2001) e Rao (2001), as práticas e os discursos moldam versões. Elas concretamente criam realidades sociais que excluem e/ou incluem.

Alguns autores discutem o estabelecimento dos rótulos atribuídos, rótulos, muitas vezes, orientados pelos próprios profissionais de saúde (Lebeer \& Rijke, 2003; Rao, 2001). No entanto, o rótulo (diagnóstico) parece representar uma faca de dois gumes. Por um lado, possibilita identificar causas, limites e possibilidades, intervenções necessárias. Simultânea e paradoxalmente, porém, contribui, muitas vezes, mais para a exclusão, já que o foco fica centrado na deficiência. A preocupação de alguns autores com a ação dos profissionais de saúde é agravada, ainda, pelo destaque que esses mesmos profissionais ocupam no cotidiano dessas crianças e famílias. Tal valorização se dá pela compreensão da estimulação ativa e intensiva, desconsiderando-se outros agentes e campos de atuação nas atividades diárias (Lebeer \& Rijke, 2003). A figura central, que detém o saber, acaba por ser o profissional ou o especialista. No entanto, identifica-se certa mudança nessa postura, já que alguns artigos revelam um destaque no modo como a família tem sido alçada a uma posição mais importante, no sentido de ser reconhecida 
como uma influência poderosa, positiva, sobre as experiências sociais de sua criança (Lebeer \& Rijke, 2003; Rao, 2001).

Mas esse olhar à família continua paradoxal, já que a ela são atribuídas influências ambivalentes, tanto pelas suas vivências emocionais, como pela necessidade dos familiares de darem mais atenção aos sinais de aquisição da criança e de seus potenciais latentes (Lebeer \& Rijke, 2003). Essa ambivalência e as fragilidades da família, no entanto, são contrapostas diante das atuais organizações dos serviços de saúde, em que se verifica uma falta de compromisso do Estado com o setor público de saúde (Abrantes-Pego, 1999). Assim, toda a carga com relação à criança com necessidades especiais recai, quase exclusivamente, sobre a família, que tem ainda de lidar com a falta de suporte diante da omissão dos serviços públicos (Abrantes-Pego, 1999) e da falta de informação (Hanson et al., 1998), o que leva a obstáculos na promoção de diversas experiências sociais de seus filhos (Baker \& Donelly, 2001).

Essa discussão de certa forma se contrapõe às importantes preocupações, apresentadas de forma relativamente simplista por Jones et al. (2001), que buscam destacar a necessidade de uma nova forma de relação do médico com o paciente, mas focando, exclusivamente, os aspectos voltados à informação/aprendizagem do paciente com relação a questões de saúde. Fala-se em colocar o paciente no centro, mas, ao que parece, este continua sendo o receptáculo de conhecimentos médicos.

Entende-se que modificações nas relações, nas crenças e nos valores de uma comunidade são lentas e dinâmicas. E, também, que a implantação de leis que defendam práticas inclusivas é fundamental. As leis ajudam, mas não são suficientes para a aceitação dos deficientes na comunidade (Parmenter, 2001). Lewis, Shadish e Lurigio (1989) frisam que os esforços para realizar a inclusão não têm tido muito sucesso, exatamente porque, sozinha, a lei não garante que o processo ocorra. No âmbito desta pesquisa, vários artigos revistos indicam essa questão e apontam no sentido do que Odom e Diamond (1998) afirmam: as políticas que mais influenciam a implantação de serviços inclusivos são as de nível local, marcadas, prioritariamente, pelas 
atitudes e crenças das pessoas que têm papéis importantes nas instituições. O trabalho de Heller et al. (1999) mostra isso claramente.

De qualquer forma, as divergências presentes, de forma cada vez mais explícita, nas publicações nos últimos anos, revelam que a concreta implantação de programas educacionais inclusivos tem feito com que aspectos positivos e, também, negativos sejam evidenciados e que a inclusão, em si, seja mesmo questionada. Esses questionamentos, no entanto, surgem a partir da implantação de tais programas, posto que revisões feitas em anos anteriores não apontaram essa visão crítica sobre o processo inclusivo (Graves \& Tracy, 1998; Odom \& Diamond, 1998; Yazlle, 2001).

\section{Comentários finais}

Com o levantamento, constatamos a complexidade do processo de inclusão, que é abordado e investigado de maneira variada. Acreditamos que a existência de tantos sentidos possíveis à palavra "inclusão" contribua para essa diversidade.

Apesar do crescente investimento e discussão, a literatura relacionada à prática da inclusão ainda conta com um número pequeno de publicações. Foi identificada, ainda, uma grande lacuna na produção de trabalhos empíricos brasileiros, carência essa evidenciada a partir das bases de dados e das palavras-chave utilizadas, além dos critérios de inclusão adotados em nossa revisão. Evidentemente, isso não assegura que, no país, não se esteja produzindo nessa área. Há, de qualquer forma, a necessidade de maiores investimentos, tendo em vista que o tema está na ordem do dia, sendo efetivado no cotidiano das escolas e pré-escolas.

Importante verificar que a forma de investigação tem se modificado, em contraposição a poucos anos atrás (Yazlle, 2001). Atualmente, a maior parte dos estudos usa estratégias qualitativas de análise, alguns processuais, acompanhando longitudinalmente o percurso da inclusão e a partir de instrumentos mais amplos (ecológicos, etnográficos). Esses estudos buscam apreender as diversas perspectivas e interlocutores envolvidos e têm a meta 
de compreensão dos processos dentro da complexidade em que o tema está envolto. Aqueles instrumentos têm inclusive possibilitado uma ruptura com um determinismo quanto ao destino dessas crianças/pessoas e quanto às possibilidades de inserção na sociedade, sendo apontados como um caminho promissor no estudo dessa questão.

Além disso, com o foco com que trabalhamos - pessoas com necessidades especiais - identificamos muitos conceitos que não são entendidos de maneira homogênea pelos que participam do e influenciam o processo. Isso faz com que a situação se revele mais diversa ainda. Assim, aspectos como “o que vem a ser deficiência?”, “qual a função da educação para deficientes?”, “eles precisam de um tratamento especializado?”, “eles podem opinar no que é traçado como ideal para eles?”, dentre outros, são pensados, a partir de diferentes perspectivas, trazendo possibilidades diversas e apresentando descontinuidades frente a essa questão.

Com relação aos profissionais de saúde, verificamos que, apesar do destacado lugar que ocupam nos processos de inclusão social, é bastante recente e escassa a investigação direta da sua ligação com essas práticas. Por outro lado, identifica-se que eles estão sendo indiretamente considerados por muitos autores. Há pontuações da relativização do lugar desses profissionais e das importantes implicações que podem ter sobre os processos, entretanto, passa a se verificar uma valorização diversa da família e de um conjunto de outras atividades.

A revisão evidencia, ainda, contradições na temática, pela forma com que as próprias pesquisas investigam as pessoas com necessidades especiais. Apesar do foco e do interesse por essa população e da discussão sobre o pertencimento como o cerne da questão, essas pessoas praticamente não são ouvidas com relação ao seu processo de inclusão, não se levando em consideração seus pontos de vista, o que elas valorizam, o que elas procuram ou precisam para se sentirem incluídas (Cook et al., 2001). Elas continuam sendo excluídas, suas vozes não sendo ouvidas. No entanto, tais explorações começam a fazer parte do cenário de discussões, podendo, com isso, abrir-se a novos caminhos, à construção de novas práticas discursivas. 
O que se evidencia nos trabalhos, no entanto, é que, de alguma forma, essas pessoas transitam por diversos espaços, sejam eles a família, a escola, a vizinhança, a comunidade, os serviços de saúde, dentre outros. Bem ou mal as pessoas com necessidades especiais fazem parte da sociedade, sendo a elas atribuídos papéis específicos. Como afirma Sawaia (2002), porém, "essa inserção nem sempre é decente e digna, sendo a grande maioria da humanidade inserida na sociedade através da insuficiência e das privações”. Portanto, concordamos com ela, quando diz que "em lugar de se referir à inclusão, em contraposição à exclusão, mais oportuno é se falar sobre a dialética exclusão/inclusão.” (Sawaia, 2002, p. 8).

O que fica claro, por fim, é que, independentemente do modo como esse processo se dê, ele deve ser pensado, discutido e efetivado, contando com a participação de todos - das pessoas com necessidades especiais, das famílias, dos profissionais, das escolas, do legislativo, do Estado e da comunidade. Como afirmam Oliver e Nicácio (1999), a inclusão é um processo social complexo. Nele deverão ser feitas inovações em diferentes dimensões: social, cultural, técnica, institucional, jurídica e política para que pessoas com necessidades especiais consigam se perceber com um outro papel na sociedade, sendo capazes de participar e assumir uma nova posição social.

Agradecimentos à FUNCAP, à FAPESP e ao CNPq.

Roriz, T. M., Amorim, K. S., \& Rossetti-Ferreira, M. C., (2005). People with special needs social/scholar inclusion: multiple perspectives and controversial discursive practices. Psicologia USP, 16 (3), 167-194.

Abstract: "Social inclusion" highlights issues such as respect for
differences and citizenship. Regarding children with special needs,
inclusion encompasses their participation in society in general and,
particularly, in regular education institutions. Due to the relevance and
controversies involved in that processes, an empiric study was 


\section{Inclusão Social/Escolar de Pessoas com Necessidades Especiais}

accomplished. Within the study, a bibliographic review was conducted, which will be here presented. Key-words were investigated in MEDLINE, PsycInfo and LILACS, mainly from 1996-2003. Selection considered works in periodicals, which deal with people with special needs and/or health practices related to this field. Nineteen papers were recovered. Eleven were empirical, having registered and analyzed situations by various methods. The issue was revealed as polemic, some authors even proposing "segregation". Health professionals were shown as having a relevant status. Some authors, however, indicate the importance of other activities/people for the inclusion processes. The establishment of diagnosis was seen paradoxically: treatment/labeling. Cultural discursive practices are indicated as of fundamental importance in the processes. Despite being the focus of investigation, people with special needs are usually not "listened". Inclusion emerges as a complex social process that must be discussed and concretely involving everybody's participation. Only then, people with special needs might acquire a new, active and recognized social position.

Index terms: School inclusion. Special educational needs. Health professionals.

Roriz, T. M., Amorim, K. S., \& Rossetti-Ferreira, M. C., (2005). L'inclusion social / scolaire des persones avec besoins speciaux: multiples perspectives et pratiques discursives divergentes. Psicologia USP, 16 (3), 167-194.

Résumé : “L'inclusion sociale” emphatize le respect aux différences et à la citoyenneté. Dans le cas des enfants avec les besoins spéciaux, l'inclusion aussi dit respect à leur participation dans les établissements éducatifs réguliers. $\mathrm{Vu}$ la pertinence et les polémiques impliquées, un étude empirique a été effectuée. Dans l'étude, une révue bibliographique a été conduite, qui sera ici présentée. Des mots-clés ont été étudiés dans MEDLINE / PsycInfo / LILAS (surtout 1996-2003). La selection a considéré des travaux publiés dans des périodiques, qui ont affaire avec des personnes avec des besoins speciales et/ou sur des pratiques de santé. 19 papiers ont eté obtenu, onze empiriques. Ils ont enregistré et analysées par diverses méthodes. L'issue est polemic, certains auteurs défendue la "ségrégation". Les professionnels de santé ont un endroit approprié. Cependant, quelques auteurs indiquent l'importance d'avoir d'autres personnes/activities pendant l'inclusion. L'établissement du diagnostic est vu paradoxalement: permet le traitement mais aussi crée un label. Des 


\section{Ticiana Melo de Sá Roriz, Katia de S. Amorim e Maria Clotilde Rossetti-Ferreira}

pratiques discursives culturelles sont indiquées comme d'importance fondamentale. En dépit d'avoir des personnes avec les besoins spéciaux comme centre des investigations, elles mêmes ne sont pas habituellement “écoutées". L’inclusion est un processus social complexe, qui doit être discuté par tout le monde. Seulement dans cette circunstance, des personnes avec les besoins spéciaux pourrons obtenir une nouvelle position sociale.

\section{Descripteurs: Inclusión escolaire. Besoins educatives speciaux. Professionnels de santé.}

\section{Referências}

Abrantes-Pego, R. (1999). Participación social en salud: um estudio de caso en Brasil. Salud Publica $M x, 41(6), 466-474$.

Arbeiter, S., \& Hartley, S. (2002). Teachers' and pupils' experiences of integrated education in Uganda. International Journal of Disability, Development and Education, 49(1), 61-78.

Baker, K., \& Donelly, M. (2001). The social experiences of children with disability and the influence of environment: A framework for intervention. Disability and Society, 16(1), 71-85.

Brasil. (1971 12 de agosto). Lei n. 5692/71. Fixa diretrizes e bases para o ensino de primeiro e segundo graus, e dá outras providências. Diário Oficial da União.

Brasil. (1996 31 de dezembro). Lei n. 9394/96. Estabelece as diretrizes e bases da educação nacional. Diário Oficial da União.

Brasile, F. (1992). Inclusion: A developmental perspective: A reinjoinder to "examining the concept of reverse integration”. Adapted Physical Activity Quarterly, 9(4), 293-304.

Chapman, L., \& Ware, J. (1999). Challenging traditional roles and perceptions: Using a transdisciplinary approach in an inclusive mainstream school. Support for Learning, 14(3), 104-109.

Cook, T., Swain, J., \& French, S. (2001). Voices from segregated schooling: Towards an inclusive education system. Disability and Society, 16(2), 293-310.

Ferreira, J. R. (2004). Políticas públicas e a universidade: uma avaliação dos 10 anos da Declaração de Salamanca. In S. Omote (Org.), Inclusão: intenção e realidade. (pp. 11-35). Marília, SP: Fundepe. 


\section{Inclusão Social/Escolar de Pessoas com Necessidades Especiais}

Ghirardi, M. (2000). Educação inclusiva: processos psicológicos e a terapia ocupacional. Revista de Terapia Ocupacional, 11(1), 13-16.

Goodman, Y. (2001). Dynamics of inclusion and exclusion: Comparing mental illness narratives of Haredi male patients and their rabbis. Culture, Medicine and Psychiatry, 25(2), 169-194.

Graves, P., \& Tracy, J. (1998). Education for children with disabilities: The rationale for inclusion. Journal of Paediatric and Child Health, 34(3), 220-225.

Hanson, M., Wolfberg, P., Zercher, C., Morgan, M., Guiterrez, S., Barnwell, D. et al. (1998). The culture of inclusion: Recognizing diversity at multiple levels. Early Childhood Research Quarterly, 13(1), 185-209.

Heller, T., Factor, A., \& Hahn, J. (1999). Residential transitions from nursing homes for adults with cerebral palsy. Disability and Rehabilitation., 21(5/6), 277-283.

Jones, R. B., Hampshire, A. J., Tweddle, S., Moult, B., \& Hill, A. (2001). The clinician's role in meeting patient information needs: Suggested learning outcomes. Medical Education, 35(6), 565-571.

Kasari, C., Freeman, S. F., Bauminger, N., \& Alkin, M. C. (1999). Parental perspectives in inclusion: effects of autism and Down Syndrome. Journal of Autism Development Disorder, 29(4), 297-305.

Lebeer, J., \& Rijke, R. (2003). Ecology of development in children with brain impairment. Child: Care, Health and Development, 29(2), 131-140.

Lewis, D., Shadish, W., \& Lurigio, A. (1989). Policies of inclusion and the mentally ill: long-term care in a new environment. Journal of Social Issues, 45(3), 173-186.

Odom, S., \& Diamond, K. (1998). Inclusion of young children with special needs in early childhood education: the research base. Early Childhood Research Quarterly, 13(1), 3-25.

Oliver, F., \& Nicácio, F. (1999). Da instituição asilar ao território: caminhos para produção de sentido nas intervenções em saúde. Revista de Terapia Ocupacional da Universidade de São Paulo, 10(2/3), 60-68.

Organização das Nações Unidas. (1990, 14 de dezembro). Resolução 45/91. Assembléia Geral das Nações Unidas, 68a Sessão Plenária. Nova York.

Organização das Nações Unidas. UNESCO. (1994). Declaração de Salamanca e linha de ação sobre necessidades educativas especiais. Brasília, DF: CORDE.

Palmer, D. S., Borthwick-Duffy, S. A., Widaman, K., \& Best, S. J. (1998). Influences on parent perceptions of inclusive practices for their children with mental retardation. American Journal on Mental Retardation, 103(3), 272-287. 
Parmenter, T. (2001). The contribution of science in facilitating the inclusion of people with intellectual disability into the community. Journal of Intellectual Disability Research, 45(3), 183-193.

Rao, S. (2001). 'A little inconvenience': Perspectives of Bengali families of children with disabilities on labelling and inclusion. Disability and Society, 16(4), 531-548.

Repper, M. (2000). The inclusion of pupils with a chronic health condition in mainstream school: What does it mean for teachers? Educational Research, 42(1), 59-72.

Roriz, T. M. (2002). A inclusão social e escolar de crianças com necessidades especiais, sob a óptica dos profissionais de saúde. Projeto de Mestrado, Departamento de Neurologia, Psiquiatria e Psicologia Médica, Universidade de São Paulo, Ribeirão Preto, SP.

Sawaia, B. (Org.). (2002). As artimanhas da exclusão: análise psicossocial e ética da desigualdade social (4a ed.). Petrópolis, RJ: Vozes.

Werneck, C. (1998). Acorda, Monstro! Escritos da Criança, (5), 107-112.

Yazlle, C. (2001). Pré-escolas convivendo com a paralisia cerebral: uma análise do processo de inclusão/exclusão. Dissertação de Mestrado, Departamento de Neurologia, Psiquiatria e Psicologia Médica, Universidade de São Paulo, Ribeirão Preto, SP.

Recebido em: 18.10.2004

Revisto em: 5.02.2005

Aceito em: 5.03.2005 